\title{
ORIGINAL ARTICLE \\ Gene expression profile of type II spinal cord decompression sickness
}

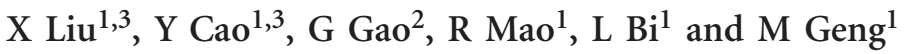

Study design: This study was an experimental, controlled, animal study.

Objective: This study was to determine the changes of molecular pathology in spinal cord decompression sickness (SC-DCS) based on a rabbit model of SC-DCS with the aid of an all-gene expression profile chip.

Setting: Qingdao, Shandong Province, China.

Methods: A gene expression profile chip containing 43803 genes was used to compare the gene expressions in the spinal cords of four male New Zealand white rabbits in the SC-DCS and control groups, respectively. Selected differentially expressed genes were identified with quantitative real-time reverse transcription polymerase chain reaction (qRT-PCR) and immunohistochemistry.

Results: The chip hybridization results showed that the SC-DCS group had nine upregulated and seventeen downregulated genes, compared with the control group. These genes were mainly related to inflammation, ion channels, the cell cycle, material transfer and apoptosis. The qRT-PCR results showed that parathyroid hormone and tumor necrosis factor alpha (TNF- $\alpha$ ) genes were upregulated compared with the control group $(P<0.01)$. However, the acyl-CoA synthetase and voltage-gated channel genes were downregulated $(P<0.05)$. The immunohistochemical staining results confirmed that there were significantly greater expression levels of TNF- $\alpha$ in the spinal cord tissues of the SC-DCS group compared with the control group.

Conclusions: The spinal cord lesions of SC-DCS involve multiple gene changes in the rabbit; however, the significance of these findings needs further research. Meanwhile, the gene expression profile chip results provide us with a better understanding of the pathogenesis of DCS.

Spinal Cord (2014) 52, 606-610; doi:10.1038/sc.2014.65; published online 6 May 2014

\section{INTRODUCTION}

Decompression sickness (DCS) is caused by tissue bubble formation from dissolved inert gases during a rapid reduction in the ambient pressure surrounding the body, as may occur with ascent from depth (for example, diving or mining) or ascent to altitude (for example, extravehicular activity from spacecraft or flying in unpressurized aircraft). ${ }^{1}$ DCS is classified as either type I or type II according to the clinical symptoms. ${ }^{2}$ Type I DCS generally presents with joint pain, rash, skin marbling or localized edema. Type II DCS includes more serious symptoms such as cardiorespiratory failure, paresis and anesthesia. Thus, DCS involving the spinal cord is defined as type II.

Spinal cord DCS (SC-DCS) is probably the most dangerous form of the commonly encountered syndromes of DCS. It often affects the lower cervical or lower thoracic regions of the spinal cord; however, its predilection for these sites is not understood. Currently, there are two major theories to account for the symptoms associated with SC-DCS. The first theory, the one for which the best experimental evidence exists, is obstruction of venous outflow of the spinal cord in the epidural plexus. This plexus is a series of blood vessels with a large crosssectional area and, therefore, a relatively slow flow. Direct experimental observations in dogs with SC-DCS confirm that bubbles coalesce in this area and eventually lead to complete cessation of blood flow. ${ }^{3}$ Once this process results in an ongoing and progressive diminution of blood flow to the cord, the second process of in situ formation of a gas phase within the tissue of the spinal cord either begins or is compounded. Pathological studies in animals suggest that in situ bubble formation takes place, and some of the aspects of the clinical picture of DCS are consistent with the development of in situ bubble formation in the spinal cord. ${ }^{4}$ However, the molecular pathological mechanism of this in situ bubble formation is far from clear.

Gene chip technology has been widely applied in various fields, including disease diagnosis, disease therapy, as well as drug screening. Data analysis enables us to understand the genetic alterations of diseases and also provides a novel approach for predicting disease incidence and progression. Using microarray chips, we examined the molecular alterations in the spinal cord tissues of a rabbit model of type II SC-DCS, which has not yet been reported. Our findings may provide a new theoretical basis for the incidence of SC-DCS.

\section{MATERIALS AND METHODS}

\section{Statement of ethics}

We certify that all applicable institutional and governmental regulations concerning the ethical use of animals were followed during the course of this research.

\section{Animals}

Male New Zealand white rabbits ( $n=20$, weight $2-3 \mathrm{~kg}$ ) from a single vendor (Shandong Lukang Inc, Jinan, Shandong, China) were housed in cages at our

${ }^{1}$ Department of Pathology, General Hospital of Jinan Military Command, Jinan, China and 2Department of Hyperbaric Medicine, No. 401, Hospital of PLA, Qingdao, China ${ }^{3}$ These two authors contributed equally to this work.

Correspondence: Professor M Geng, Department of Pathology, General Hospital of Jinan Military Command, No. 25, Shifan Road, Jinan, Shandong Province 250031, China. E-mail: gm2227@126.com

Received 8 February 2014; accepted 1 April 2014; published online 6 May 2014 
animal care facility, where they acclimated for 5 days before any procedures. They were fed standard rabbit chow twice daily with free access to water.

\section{Subjects and experimental series}

On the basis of a previous report and our preliminary study, animals were placed into a hyperbaric chamber (YC3800/0.3-36 VII, Yantai Moon Hyperbaric Oxygen Chamber Co, Ltd). The chamber was pressurized with room air at an absolute pressure of $0.7 \mathrm{MPa}$ within $5 \mathrm{~min}$, and the pressure was kept constant for $60 \mathrm{~min}$. Then, the chamber was decompressed gradually over a 5 -min period at a constant rate. Next, the animals exhibited acroparalysis in one or more than one limb, suggesting the successfully established type II SC-DCS model..$^{5}$ The control animals were also placed in a chamber, which was decompressed to normal conditions according to the naval air decompression table. ${ }^{6}$ Within 3 days after treatment, no DCS was found in these control animals.

Within $30 \mathrm{~min}$ after removal from the chambers, DCS $(n=10)$ and control $(n=10)$ animals were anesthetized with $0.1 \mathrm{ml} \mathrm{kg}^{-1}$ ketamine and lumianning. Fresh thoracic spinal cord tissues were dissected, and the animals were killed. For molecular biology analysis, some of the tissues were placed into liquid nitrogen followed by preservation in a freezer at $-80{ }^{\circ} \mathrm{C}$. Two samples were randomly selected from each experimental group and were used for microarray analysis. Other samples were fixed with $4 \%$ formaldehyde, embedded with paraffin, sectioned and used for morphological analysis under a light microscope or for immunohistochemistry.

\section{RNA isolation}

Total RNA from the spinal cord of the DCS group or the control group was isolated using the Trizol reagent, according to the manufacturer's instructions (Invitrogen Life Technologies, Carlsbad, CA, USA). Total RNA from each sample was quantified using a NanoDrop ND-1000 spectrophotometer (Thermo Scientific, Waltham, MA, USA), and the RNA integrity was assessed using standard denaturing agarose gel electrophoresis. The RNA was further purified on an affinity resin column (RNeasy; Qiagen, Chatsworth, CA, USA).

\section{Microarray expression analysis}

To determine the relative gene expression profiles in SC-DCS, we analyzed the relative abundance of mRNA using microarray analysis with the Agilent Array platform (Agilent Technologies, Santa Clara, CA, USA). Sample preparation and microarray hybridization were performed based on the manufacturer's standard protocols. In brief, $1 \mu \mathrm{g}$ of total RNA from each sample was amplified and transcribed into fluorescent cRNA by using Agilent's Quick Amp Labeling protocol (version 5.7, Agilent Technologies). The labeled cRNAs were hybridized onto the Whole Rabbit Genome Oligo Microarray $(4 \times 44 \mathrm{~K}$, Agilent Technologies). After washing the slides, the arrays were scanned by an Agilent scanner (G2505B). Agilent Feature Extraction software (version 10.7.3.1) was used to analyze the acquired array images. Quantile normalization and subsequent data processing were performed using the GeneSpring GX v11.5.1 software package (Agilent Technologies). The differentially expressed genes between the DCS group spinal cords and the control group spinal cords were filtered based on fold-change cutoffs of $\leqslant 0.5$ and $\geqslant 2$ for downregulated and upregulated genes, respectively.

\section{Quantitative real-time reverse transcription polymerase chain reaction ( $q R T-P C R)$}

qRT-PCR was performed as described previously. ${ }^{7}$ Reverse transcription was performed using $1 \mu \mathrm{g}$ of total RNA from each sample and the MMLV Reverse Transcriptase 1st Strand cDNA Synthesis Kit (Illumina, San Diego, CA, USA), according to the manufacturer's instructions. QRT-PCR was performed using SYBR Green in a Rotor-gene 3000 thermal cycler (Corbett Research, Sydney, New South Wales, Australia). The PCR primer sequences were designed for the selected genes and $\beta$-actin, which served as the constitutive control, based on the gene sequences reported in GenBank and were chemically synthesized (Table 1). The specificity of the PCR was confirmed by examining the dissociation reaction plot subsequent to qRT-PCR. PCR of each sample was conducted in triplicate. Data were analyzed using the comparative cycle threshold method.
Table 1 Primer sequences used for qRT-PCR

\begin{tabular}{|c|c|c|c|}
\hline Genebank ID & Primer sequences $\left(5^{\prime}-3^{\prime}\right)$ & $\begin{array}{c}\text { Annealing } \\
\text { temperature }\left({ }^{\circ} \mathrm{C}\right)\end{array}$ & $\begin{array}{l}\text { Product } \\
\text { size (bp) }\end{array}$ \\
\hline$\beta$-actin (ACTB) & AAGTGCTTCTAGGCGGACTGTTA & 60 & 89 \\
\hline NM_001101683 & ATGCCAATCTCGTCTCGTTTCT & & \\
\hline XM_002708821 & $\begin{array}{l}\text { GAGAGGGTAGAATGGCTGCG } \\
\text { TTGTGATGGCTGTCAACTGAGA }\end{array}$ & 60 & 140 \\
\hline NM_001082263 & $\begin{array}{l}\text { TTCTCTTTCCTGCTCGTGGC } \\
\text { ACTTGCGGGTTTGCTACTACG }\end{array}$ & 60 & 1094 \\
\hline XM_002710791 & $\begin{array}{l}\text { CAGTTGCAGCCTTCTTATCACTAC } \\
\text { GACACGCTTGGATTTCTCTTTC }\end{array}$ & 60 & 247 \\
\hline XM_002713013 & $\begin{array}{l}\text { GAAACCTTCGCAGAAATCAGAGT } \\
\text { GCTTCCAAATCAAAGAGCACC }\end{array}$ & 60 & 332 \\
\hline
\end{tabular}

Abbreviation: qRT-PCR, quantitative real-time reverse transcription polymerase chain reaction.

\section{Immunohistochemistry}

The spinal cord tissues were fixed in formalin, embedded in paraffin, and cut into $4-\mu \mathrm{m}$-thick sections. The sections were pretreated, dewaxed in xylene and hydrated before antigen retrieval. After endogenous peroxidase inhibition, the sections were incubated with a polyclonal antibody against rabbit tumor necrosis factor alpha (TNF- $\alpha$; 1:300; BG-A042081, Bluegene, Shanghai, China) overnight at $4{ }^{\circ} \mathrm{C}$. After thorough washing with phosphate-buffered saline, the corresponding secondary antibodies were applied and incubated at room temperature for $30 \mathrm{~min}$. Reaction products were visualized by incubation with $3,3^{\prime}$-diaminobenzidine and then counterstained with hematoxylin. Negative controls were prepared by substituting the primary antibody with isotype-matched irrelevant antibody.

\section{Evaluation of immunostaining}

TNF- $\alpha$ staining was judged by two pathologists (Mao RQ and Cao YC) who were blinded to any clinical details related to the cases. TNF- $\alpha$-positive cells were counted from 10 randomly selected high-power fields. The percentage of positive cells among the total number of cells counted was calculated to obtain the TNF- $\alpha$-positive rate (\%).

\section{Statistical analysis}

All statistical analyses were performed with SPSS version 11.0 software (SPSS, Chicago, IL, USA). A $P$-value $<0.05$ was considered statistically significant.

\section{RESULTS}

\section{Pathology}

Under a light microscope, vacuolar lesions were observed in the white matter lesions of the spinal cord in DCS animals (Figure 1b). In addition, axons undergoing Wallerian degeneration with loosened and swelling tissue structures, accompanied with glial cell proliferation, were observed in the spinal cord tissues of DCS animals. However, an intact tissue structure of the spinal cord as well as normal morphology of nerve cells were found in control animals (Figure 1a).

Differential gene expression between SC-DCS and control tissues Using the Whole Rabbit Genome Oligo Microarray, we analyzed the gene expression of spinal cord tissues obtained from DCS and control animals. Gene expression analysis showed that the levels of 609-984 genes were upregulated, whereas 488-948 genes were downregulated in the DCS animals as compared with the controls. Nine genes showed more than a twofold increase (Table 2) and 17 genes exhibited over a twofold decrease (Table 3), simultaneously in DCS animals. These differentially expressed genes were distributed among different functional categories, such as inflammation, ion channels, the cell cycle, material transport and transcription factors. 

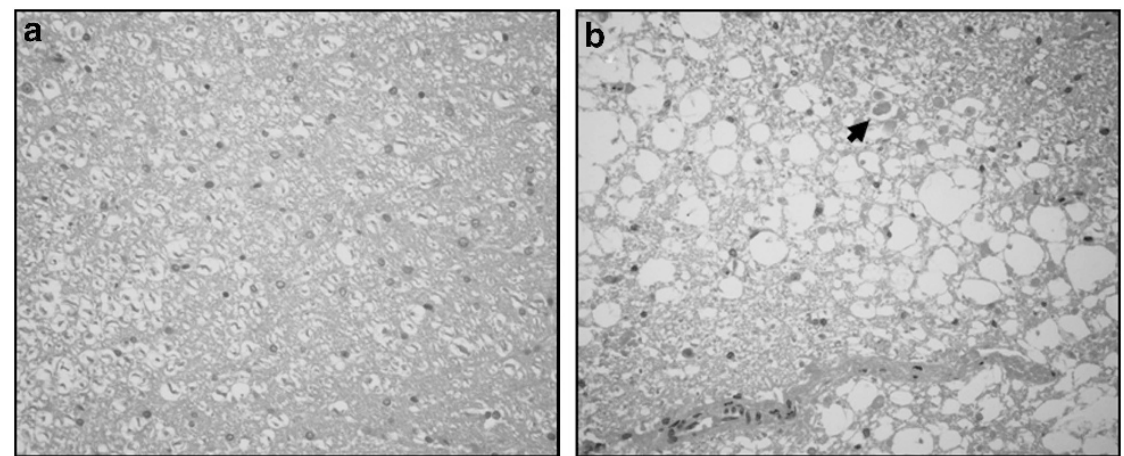

Figure 1 Compared with the control (a), abundant vacuoles were found in the white matter of spinal cord tissues of DCS animals (b). Axonal swelling (arrow), interstitial hemorrhage and congestion of blood vessels were also detected in the DCS spinal cord. ( $\times 40$ Magnification).

Table 2 Upregulated genes (more than twofold increase) in SC-DCS tissues compared with the controls

\begin{tabular}{|c|c|c|}
\hline Gene & Genebank ID & Description \\
\hline PTH & XM_002708821 & $\begin{array}{l}\text { Oryctolagus cuniculus } \\
\text { parathyroid hormone }\end{array}$ \\
\hline $\begin{array}{l}\text { Cyclin A1-interacting } \\
\text { protein } 1\end{array}$ & XM_002718838 & $\begin{array}{l}\text { Oryctolagus cuniculus inhibitor } \\
\text { of CDK, cyclin A1-interacting } \\
\text { protein } 1\end{array}$ \\
\hline $\begin{array}{l}\text { Meiosis-expressed } \\
\text { gene 1-like }\end{array}$ & XM_002717460 & $\begin{array}{l}\text { Oryctolagus cuniculus } \\
\text { meiosis-expressed gene 1-like }\end{array}$ \\
\hline TNF & NM_001082263 & Oryctolagus cuniculus TNF \\
\hline cDNA clone naf35d11.x1 3' & DN886250 & Unknown function \\
\hline 28S Ribosomal protein S33 & XM_002722065 & $\begin{array}{l}\text { Oryctolagus cuniculus } 28 \mathrm{~S} \\
\text { ribosomal protein S33, } \\
\text { mitochondrial-like }\end{array}$ \\
\hline cDNA clone nbc43a09.y1 & EB378780 & Unknown function \\
\hline cDNA clone naf25d04.y1 & DN884820 & Unknown function \\
\hline DNMT3 & XM_002716753 & $\begin{array}{l}\text { Oryctolagus cuniculus NOP2/ } \\
\text { Sun domain family, member } 3\end{array}$ \\
\hline
\end{tabular}

Abbreviations: CDK, cyclin dependent kinase; cDNA, complementary DNA; DNMT, DNA methyltransferase 3; PTH, parathyroid hormone; SC-DCS, spinal cord decompression sickness; TNF, tumor necrosis factor.

Validation of the microarray data using qRT-PCR

Using the qRT-PCR technique, we validated the microarray chip data. To this end, parathyroid hormone and TNF genes, both of which were upregulated in the microarray analysis, as well as acyl-CoA synthetase and voltage-gated channel genes, both of which were downregulated in the microarray analysis, were included. Compared with the controls, the expression levels of parathyroid hormone and TNF genes were elevated (parathyroid hormone, 6.18-fold increase; TNF, 6.46-fold increase), whereas the levels of acyl-CoA synthetase and voltage-gated channel genes were decreased (acyl-CoA synthetase, 2.28-fold decrease; voltage-gated channel, 3.16-fold decrease) in the DCS animals (all $P<0.05)$. These results were consistent with the microarray hybridization data, confirming the microarray analysis results.

TNF- $\alpha$ protein expression in the spinal cord

TNF- $\alpha$-positive staining, with the appearance of brown granules, was detected in the cytoplasm of neurons in the gray matter and glia in the white matter of spinal cord tissues. Strong immunostaining of TNF- $\alpha$ and an increased number of cells expressing TNF- $\alpha$ were
Table 3 Downregulated genes (less than twofold increase) in SC-DCS tissues compared with the controls

\begin{tabular}{|c|c|c|}
\hline Gene & Genebank ID & Description \\
\hline CAP18 & NM_001082305 & Inflammation \\
\hline MRP-8 & D17405 & $\begin{array}{l}\text { Inflammation and Stress } \\
\text { response }\end{array}$ \\
\hline cDNA clone nag35g07.y1 & DN890616 & Unknown function \\
\hline Corticostatin-6 & NM_001082300 & Defensins, inflammation \\
\hline Bactericidal & U61270 & Inflammation \\
\hline $\begin{array}{l}\text { mp129VL antibody variable } \\
\text { domain mRNA }\end{array}$ & AY171875 & Unknown function \\
\hline cDNA clone nbc39h06.y1 & EB378307 & Unknown function \\
\hline Leukocyte protein & NM_001082325 & Immune \\
\hline LUM & NM_001195680 & Cell matrix \\
\hline $\begin{array}{l}\text { Acyl-CoA synthetase short-chain } \\
\text { family member } 2\end{array}$ & XM_002710791 & Lipid metabolism \\
\hline Interleukin-12A-like & XM_002716291 & Inflammation \\
\hline $\begin{array}{l}\text { Leucine-rich repeat-containing } \\
\text { protein } 48 \text {-like }\end{array}$ & XM_002724076 & Metabolism \\
\hline $\begin{array}{l}\text { AER61 glycosyltransferase, } \\
\text { transcript variant } 1\end{array}$ & XM_002713300 & Cell cycle \\
\hline cDNA clone nbc25f01.y1 & EB376213 & Unknown function \\
\hline cDNA clone nbc32h08.y1 & EB377267 & Unknown function \\
\hline Voltage-gated channel like 1 & XM_002713013 & Ion channel \\
\hline Defensin NP-4 & NM_001082299 & Defensins, inflammation \\
\hline
\end{tabular}

Abbreviations: CAP18, 18-kDa cationic antimicrobial protein; cDNA, complementary DNA; LUM, lumican; MRP-8, macrophage migration inhibitory factor-related protein-8; SC-DCS, spinal cord decompression sickness.

found in the spinal cord in the gray matter and the white matter in DCS animals (DCS, $16.3 \pm 4.5$ per high-power field, $n=10$; Control, $6.5 \pm 3.1$ per high-power field, $n=10 ; P=0.003$; Figure 2).

\section{DISCUSSION}

Gene expression profile analysis showed that genes related to inflammation, the cell cycle, methylation, apoptosis and protein translation were upregulated in injured spinal cords of DCS animals. Since it has been reported that TNF is involved in the progression of DCS, ${ }^{8,9}$ we were quite interested in the altered expression of TNF in DCS animals. We further confirmed the elevated expression of TNF in spinal cord tissues of DCS animals from the transcription and protein expression levels. TNF- $\alpha$ and TNF- $\beta$ are two subunits of TNF, and TNF- $\alpha$ accounts for $75-95 \%$ of the total biological activities of 

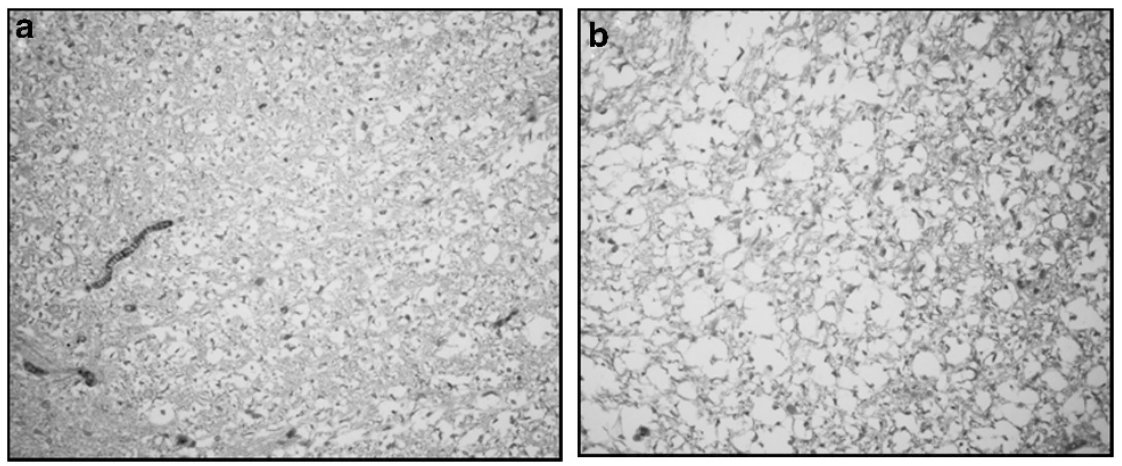

Figure 2 Immunohistochemical analysis of TNF- $\alpha$ expression in the spinal cord. Compared with the control (a), an increased number of cells expressing TNF- $\alpha$ was observed in the white matter of spinal cord tissues of DCS animals (b). ( $\times 40$ Magnification).

TNF. In the nervous system, TNF- $\alpha$ is mainly expressed by microglia, astrocytes, blood-borne macrophages, neurons and vascular endothelial cells. Being a cytokine with various biological actions, TNF- $\alpha$ participates in immune and inflammatory responses. ${ }^{8,9}$ TNF exerts its biological activities by binding to its receptor on the cell membrane. After binding, TNF triggers signal transduction pathways, including apoptosis and the nuclear factor kappa-light-chain-enhancer of activated B cells and JNK pathways. ${ }^{10,11}$

Second, the upregulation of the DNA methyltransferase 3 (DNMT3) gene indicated that DNA methylation might contribute to spinal cord injury in DCS. DNMT is required for the establishment and maintenance of DNA methylation. In mammalian cells, three active methyltransferases, namely DNMT1 and DNMT3A/3B, and one inactive methyltransferase, DNMTL, were identified. DNMT1 contributes to the maintenance of DNA methylation, and DNMT3 is required for de novo methylation. DNA methylation is one of the most important mechanisms of mammalian epigenetics and regulates cell differentiation as well as individual development by affecting the stability of the chromosome structure, the selectivity of gene expression, and DNA replication, recombination and repair. ${ }^{12,13}$ Finally, we also observed increased expressions of parathyroid hormone, cyclin A1-interacting protein 1 and meiosis-expressed gene-1-like genes, suggesting the disease complexity of DCS.

Seventeen genes related to inflammation, ion channels, lipid metabolism and signal transduction were found to be downregulated in DCS animals. Of these 17 genes, the $18-\mathrm{kDa}$ cationic antimicrobial protein, macrophage migration inhibitory factor, defensin-4, interleukin-12A, interferon- $\alpha \mathrm{A}$ and neutrophil sterilization protein are involved in inflammation, immune response and stress. ${ }^{14-17}$ The leucine-rich repeat (LRR) family member LRRC48 was obviously downregulated. The LRR protein is widely distributed in eukaryotic and prokaryotic cells and tissues. Some of the LRR proteins are specifically expressed in the nervous systems. Serving as cell adhesion or ligand-binding proteins, these proteins participate in several physiological activities of nerves, including synapse formation, neurite outgrowth and development, and the transfer and release of neurotransmitters. Until now, the effect of LRRC48 in DCS has been unclear. We speculate that the downregulated LRRC48 in spinal cord tissues of DCS animals may contribute to the abnormal transfer of neurotransmitters. ${ }^{18,19}$ Our results further demonstrated that the voltage-gated channel gene was altered in DCS animals, which may be because of altered neuronal functions. ${ }^{20}$ Furthermore, some of the differentially expressed genes could be identified by the sequence number on Genebank, whereas their functions remain unknown and need to be clarified.
In conclusion, we analyzed the gene expression in spinal cord tissues of DCS animals using gene expression profiling and identified multiple differentially expressed genes involved in the incidence and progression of DCS. Our findings reveal the disease complexity of DCS and confirmed the previous hypothesis regarding the involvement of the TNF gene in DCS. Thus, our study provides an experimental basis for understanding the mechanism of spinal cord injury in DCS.

\section{DATA ARCHIVING}

There were no data to deposit.

\section{CONFLICT OF INTEREST}

The authors declare no conflict of interest.

\section{ACKNOWLEDGEMENTS}

This study was supported by the 'Twelfth Five Years Plan' for Medical Science and Technology of PLA (grant no. CWS11J241).

1 Vann RD, Moon RE, Freiberger JJ, Denoble PJ, Dear GL, Stolp BW et al. Decompression illness diagnosis and decompression study design. Aviat Space Environ Med 2008; 79: 797-798.

2 Yoshiyama M, Asamoto S, Kobayashi N, Sugiyama H, Doi H, Sakagawa H et al. Spinal cord decompression sickness associated with scuba diving: correlation of immediate and delayed magnetic resonance imaging findings with severity of neurologic impairment-a report on 3 cases. Surg Neurol 2007; 67: 283-287.

3 Hallenbeck JM. Cinephotomicrography of dog spinal vessels during cord-damaging decompression sickness. Neurology 1976; 26: 190-199.

4 Neuman TS. Arterial gas embolism and decompression sickness. News Physiol Sci 2002; 17: 77-81.

5 Gao GK, Wu D, Shi YL, Yang Y, Wang SX, Yang RQ. Effects of hyperbaric oxygen on spinal cord evoked potential in rabbits with experimental decompression sickness. Chin J Naut Med Hyperbar Med 2004; 11: 94-96.

6 Tao HY, Liu WW. Diving tablets. In: Tao HY and Zhang H (eds). Prevention and Control of Decompression Disease, 1st edn, The press of the Second Military Medical University: Shanghai, China, 2011, pp 59-65.

7 Liu X, Wang L, Zhang S, Lin J, Zhang S, Feitelson MA et al. Mutations in the $\mathrm{C}$-terminus of the $\mathrm{X}$ protein of hepatitis $\mathrm{B}$ virus regulate Wnt-5a expression in hepatoma Huh7 cells: cDNA microarray and proteomic analyses. Carcinogenesis 2008; 29: 1207-1214.

8 Chen Y, Montcalm-Smith E, Schlaerth C, Auker C, McCarron RM. Acclimation to decompression: stress and cytokine gene expression in rat lungs. J Appl Physiol 2011; 111: 1007-1013.

9 Bigley NJ, Perymon H, Bowman GC, Hull BE, Stills HF, Henderson RA. Inflammatory cytokines and cell adhesion molecules in a rat model of decompression sickness. J Interferon Cytokine Res 2008; 28: 55-63.

10 Zou JY, Crews FT. TNF alpha potentiates glutamate neurotoxicity by inhibiting glutamate uptake in organotypic brain slice cultures: neuroprotection by NF kappa B inhibition. Brain Res 2005; 1034: 11-24.

11 Biglari B, Büchler A, Swing T, Biehl E, Roth HJ, Bruckner T et al. Increase in soluble CD95L during subacute phases after human spinal cord injury: a potential therapeutic target. Spinal Cord 2013; 51: 183-187. 
12 Geiman TM, Muegge K. DNA methylation in early development. Mol Reprod Dev 2010; 77: 105-113.

13 Sen GL, Reuter JA, Webster DE, Zhu L, Khavari PA. DNMT1 maintains progenitor function in self-renewing somatic tissue. Nature 2010; 463: 563-567.

14 Nagaoka I, Tamura H, Hirata M. An antimicrobial cathelicidin peptide, human CAP18/ LL-37, suppresses neutrophil apoptosis via the activation of formyl-peptide receptorlike 1 and P2X7. J Immunol 2006; 176: 3044-3052.

15 Calandra T, Roger T. Macrophage migration inhibitory factor: a regulator of innate immunity. Nat Rev Immunol 2003; 3: 791-800.
16 Selsted ME, Ouellette AJ. Mammalian defensins in the antimicrobial immune response. Nat Immunol 2005; 6: 551-557.

17 Vignali DA, Kuchroo VK. IL-12 family cytokines: immunological playmakers. Nat Immunol 2012; 13: 722-728.

$18 \mathrm{Xu}$ G, Wu MH, Li GY. Progress of LRR transmembrance protein function in nervous system. Prog Biochem Biophys 2012; 39: 314-318.

19 Ye Z, Ting JP. NLR, the nucleotide-binding domain leucine-rich repeat containing gene family. Curr Opin Immunol 2008; 20: 3-9.

20 Elinder F, Nilsson J, Arhem P. On the opening of voltage-gated ion channels. Physio Behav 2007; 92: 1-7. 